REVISTA ANDALUZA DE ANTROPOLOGÍA. NÚMERO 1: ANTROPOLOGÍAS DEL SUR.

JUNIO DE 2011

ISSN 2174-6796

[pp. 110-113]

http://dx.doi.org/10.12795/RAA.2011.i01.07

\title{
BRIONES, RAFAEL (dir.), SOL TARRÉS, ÓSCAR SALGUERO, ESTEFANÍA FERNÁNDEZ, CLARA MACÍAS Y VERÓNICA SUÁREZ (2010). ¿Y tú (de) quién eres? Minorías religiosas en Andalucía. Barcelona: Editorial Icaria, 611 pp.
}

\author{
Susana Moreno Maestro \\ Grupo de Investigación GEISA \\ Universidad de Sevilla.
}

El libro ¿Y tú (de) quién eres? Minorías religiosas en Andalucía es el resultado de una investigación encargada por la Fundación Pluralismo y Convivencia del Ministerio de Justicia. Con este encargo, se amplía la serie de estudios sobre minorías religiosas no católicas en el Estado español impulsados desde esta Fundación, habiéndose editado ya monografías sobre Cataluña, Valencia, Madrid, Castilla la Mancha, Canarias y Aragón.

Para Andalucía, este trabajo se encarga al profesor e investigador del Departamento de Antropología Social de la Universidad de Granada, Rafael Briones, reconocido especialista del hecho religioso. La decisión de confiar la investigación a un experto en religiones, y no en migraciones, si bien nos parece acertada, pues no toda minoría religiosa constituye a la vez una minoría étnica y/o nacional, ni viceversa, no nos puede hacer perder de vista que, como señala el propio director de la investigación al principio del texto, "la razón más poderosa del pluralismo religioso cada vez más visible y potente ha sido el crecimiento de la inmigración en los últimos quince años" (p. 31). Y de eso es consciente la Fundación 
Pluralismo y Convivencia cuando nos plantea en la Presentación Institucional del libro "la compleja relación entre religión y cultura" (p.21). Pero, ¿por qué este encargo? Rafael Briones nos habla en su presentación del "especial interés" de la Fundación por estudiar cómo influyen los referentes religiosos en la integración de los inmigrantes. ¿Se quiere, entonces, un mapa de entidades de minorías religiosas o un mapa de las entidades religiosas constituidas por minorías étnicas y/o nacionales?

Qué duda cabe que la diversidad actual de grupos religiosos es, en buena medida, resultado de la presencia en nuestra tierra de colectivos de inmigrantes, pero como demostrarán sobradamente Briones y su equipo de investigación a lo largo del texto, existe un pluralismo religioso más allá de los inmigrantes. Quizás por ello, la investigación se deja en manos de un antropólogo que, a lo largo de su trayectoria investigadora, ha demostrado, con creces, su mirada holística en el análisis de las realidades sociales.

El libro abre con la Presentación Institucional seguida de la obligada introducción del director de la investigación. En ella se explica no solo qué es lo que nos disponemos a leer sino, también, y esto nos parece muy oportuno, sitúa en la trayectoria investigadora de quienes realizan el trabajo. Sin duda, esto es de agradecer, pues aclara el por qué se ha encomendado tal labor a Rafael Briones y por qué este ha contado con el resto de los componentes del equipo, resaltando la también profesora e investigadora Sol Tarrés, una de las mejores conocedoras del Islam en Andalucía.

La publicación consta de tres partes. En la primera se recogen tres capítulos de cuestiones fundamentales para el análisis de los grupos religiosos: sus procesos de institucionalización (o no), estructura y funcionamiento de los grupos y la cuestión de la visibilidad religiosa. Sin duda, la sistematización teórica que se hace sobre estas cuestiones ayuda a tener las mentes preparadas para analizar el aluvión de grupos que se presentarán en la segunda parte del libro: se hace un repaso a la tipología de Max Weber sobre criterios de legitimación y tipos de autoridad, se trae la tradición durkheimiana para analizar las maneras de distribuir y gestionar el poder, se utiliza, entre otros muchos conceptos, el de "instituciones totales" de Goffman... Sin embargo, leyendo estos capítulos se constata que no se trata únicamente de una contextualización y explicación del marco teórico, sino que se adelantan conclusiones de datos que aparecerán más adelante en el texto, en la parte principal del libro. Así, se habla de grupos religiosos todavía no descritos como referencias ilustrativas de distintos grados de institucionalización o se colocan en diferentes modelos, según su estructura y funcionamiento, a entidades que se describirán posteriormente. Lo cierto es que se van adelantando cuestiones a la propia presentación de los datos. Pensamos que, quizás, esta aplicación del marco teórico debiera ir en el tratamiento mismo de los grupos, pues de lo contrario, como después ocurrirá, se hacen demasiado descriptivos varios de los casos tratados sin que algunos de ellos se acompañen de análisis e interpretación. En consecuencia, estos tres capítulos que 
componen la primera parte del libro se acercan más a lo que serían las conclusiones que a una introducción. En la segunda parte se presenta la gran diversidad religiosa existente hoy en Andalucía: el primer capítulo se dedica a las iglesias evangélicas, el segundo exclusivamente a la Iglesia Filadelfia y se continúa con las Iglesias Ortodoxas, Testigos de Jehová, "Iglesia mormona", Adventistas, Musulmanes, Judaísmo, Budismo, Hinduismo, Fé Bajāí y "otros grupos".

Es impecable la labor de rastreo realizada por todos los autores recogiendo tanto grupos formalizados y registrados en instituciones públicas como otros no registrados y con escaso grado de institucionalización, llegando incluso a añadirse nuevos grupos en el periodo mismo de redacción del trabajo. Dicho esto, hay que señalar, también, que si bien es verdad que el conjunto de este tiene ya de por sí un valor importante -facilitando futuros trabajos a muchos investigadores-, la calidad y el gusto por el detalle de las descripciones de algunos grupos contrasta con la pobreza de lo recogido sobre otros, percibiéndose durante todo el libro un desequilibrio evidente en cuanto al tratamiento de las distintas entidades. Por poner solo un par de ejemplos, en algunas ocasiones hay una descripción minuciosa de los espacios de culto, mientras que en otras apenas se mencionan; y para algunas entidades se describen las funciones de los líderes religiosos contrastando la información dada en entrevistas con observaciones del trabajo de campo, mientras para otras no se sale del discurso oficial del grupo. Indudablemente, también cuenta en este desequilibrio la existencia o no de trabajos previos de los diversos investigadores sobre los colectivos religiosos que aquí tratan, siendo evidente la existencia de trabajos de campo intensivos con algunas de las minorías religiosas anteriores a este encargo. Aún así, pensamos que esta situación es en gran parte inevitable cuando el objetivo de la investigación es realizar un registro de las entidades, en este caso de las minorías religiosas, existentes en un territorio tan extenso y complejo como el andaluz.

La tercera y última parte del libro vuelca una serie de consideraciones finales hechas a partir de los datos expuestos anteriormente. Se compone de cuatro capítulos en los que se analizan cuestiones de indudable relevancia en torno a las minorías religiosas: actividades que realizan (hacia adentro y hacia afuera de los propios grupos), espacios de culto y cementerios, necesidades (materiales e inmateriales) y maneras de solventarlas, y un último capítulo dedicado a la importancia del diálogo interreligioso, dándonos a conocer las iniciativas que se plantean hoy desde diferentes comunidades religiosas y otras instancias no religiosas.

La publicación se cierra con Anexos, Bibliografía, Sitios web sobre diálogo interreligioso y un Directorio con las entidades religiosas descritas.

Aunque no desmerezcan el valor de la obra, sí nos gustaría señalar lo que entendemos como dos deficiencias que podrían haber sido evitadas. La primera es citar casi exclusivamente, al tratar de las subvenciones a las diferentes entidades, las concedidas 
por parte de la Fundación que patrocina el trabajo, sin apenas mencionar otras fuentes de ayudas o subvenciones. La segunda es la inexistencia de referencias bibliográficas dentro de cada texto, agrupándose toda la bibliografía al final del libro, con lo que, en ocasiones, es difícil diferenciar lo que es fruto de la investigación o son consideraciones del investigador de lo que son, o deberían ser, citas bibliográficas. Algún error, ya de menos importancia, también hemos observado en la bibliografía, como es la adjudicación inadecuada de algunas publicaciones a autores distintos a los que las realizaron debido, quizá, a la coincidencia de apellidos.

Más allá de estas consideraciones, ellibro posee gran interés por ser la primera recopilación de este tipo que se realiza en Andalucía. Briones y su equipo nos ofrecen, sin duda, un gran trabajo a partir del cual poder desarrollar cantidad de análisis y extraer importantes consideraciones. Indudablemente, será una herramienta de gran utilidad para todos los investigadores del hecho religioso, de la diversidad cultural, las relaciones interétnicas y las migraciones, aunque no solo para ellos, pues también interesará a los estudiosos de las formas de organización grupal, de las relaciones de poder, de los liderazgos y otros temas conexos. 